DOI: http://dx.doi.org/10.18569/tempus.v11i3.2259

\title{
Apoio matricial em Saúde Mental na Atenção Primária à Saúde: potencialidades e desafios
}

\author{
Matrix support in Mental Health in Primary Health Care: \\ potentialities and challenges
}

\section{Apoyo Matricial en Salud Mental en la Atención Primaria de Salud: Potencialidades y retos}

\author{
Fabiane Aquino Lourenço de Araujo ${ }^{1}$ \\ Mariana Chaves Aveiro ${ }^{2}$
}

\begin{abstract}
RESUMO: O apoio matricial constitui um novo arranjo organizacional e metodologia para a gestão do trabalho em saúde, objetivando a relação horizontal entre distintas especialidades e níveis de atenção. A residência multiprofissional participou de algumas iniciativas por meio dos seus diferentes atores. Este trabalho buscou se aproximar do apoio matricial sob a ótica de profissionais que atuam em cinco serviços de saúde mental no município de Santos - SP. Trata-se de estudo qualitativo, envolvendo entrevistas semiestruturadas junto a profissionais de diferentes especialidades. Os dados obtidos foram analisados com base na metodologia da análise temática e divididos em três categorias. Os resultados evidenciam que a proposta do apoio matricial não foi incorporada com clareza por todos os profissionais, e que a maior dificuldade relatada para sua concretização foi com os profissionais da categoria médica. Foi encontrado também que a parceria entre os serviços, a universidade e a secretaria municipal de saúde é um importante ponto de apoio para a efetivação do matriciamento. Porém, ainda são necessários investimentos em uma política no município que possa fortalecer o apoio matricial, além de espaços de educação permanente para os trabalhadores. Para que esse novo arranjo organizacional possa ser efetivado, são necessários a articulação e o trabalho coletivo de todos os atores que buscam a integralidade da atenção. Construir reflexões sobre estas experiências torna-se essencial, problematizando o fazer dos profissionais neste campo e reconhecendo as dificuldades e os avanços.
\end{abstract}

Palavras-chave: Saúde mental, Atenção Primária à Saúde, Serviços de saúde, Saúde Pública.

ABSTRACT: The matrix support establishes a new organizational arrangement and methodology for managing the work in the Health area, aiming the horizontal relation among different specialties and attention levels. The multidisciplinary residency engaged a few initiatives throughout its different agents. This study focused on approaching the matrix support from the point of view of the professionals working in five Mental Health Services located in Santos (SP). This is a qualitative study, involving semi-structured interviews with professionals form different specialties. The data collected were analyzed according to the Thematic Analysis methodology, and divided into

1 Terapeuta Ocupacional pós graduada em Atenção à Saúde (UNIFESP/BS) e em Terapia Ocupacional aplicada a Neurologia (Instituto Israelita de ensino e pesquisa Albert Einstein). Prefeitura Municipal de São Paulo. São Paulo, São Paulo, Brasil. E-mail: fa.bi_araujo@yahoo.com.br

2 Doutora em Fisioterapia - UFSCar; Professora Adjunta de Fisioterapia. Universidade Federal de São Paulo - Campus Baixada Santista, Departamento de Ciências do Movimento Humana. São Paulo, Brasil. E-mail: mariana.aveiro@, unifesp.br 
three categories. The results demonstrate that the matrix support proposition was not incorporated clearly by all the professionals, and that the main difficulty reported for its concretion was related to professionals from the medical area. In addition, the results show that the partnership between the Health Services, the University and the Municipal Health Office is an important supporting point for the matrix support effectiveness. However investments are still needed in developing a policy that strengthens the matrix support in the city, and in creating permanent educational sites for the health professionals. In order to enable this new organizational arrangement, the articulation and a collective endeavor from all the health agents that pursue the wholeness of the assistance are required. To build reflections about these experiences becomes essential, problematizing the work of the professionals in this field and the acknowledgement of the difficulties and the advances.

Keywords: Mental Health, Primary Health Care, Health Services, Public Health.

RESUMEN: El apoyo matricial constituye una nueva combinación organizacional y metodológica para la gestión del trabajo en la salud, con el objetivo de alcanzar la relación horizontal entre distintas especialidades y niveles de atención. La residencia multiprofesional hizo parte de algunas iniciativas por medio de sus diferentes actores. Este trabajo buscó aproximar-se del apoyo matricial desde la perspectiva de los profesionales que actúan en cinco servicios de salud mental en el municipio de Santos - SP. Se trata de un estudio cualitativo, envolviendo entrevistas semiestructuradas junto a profesionales de diferentes especialidades. Se analizaron los datos obtenidos a través de las metodologías temáticas de análisis y se dividieron en tres categorías. Los resultados evidencian que la propuesta del apoyo matricial no fue incorporada con claridad por todos los profesionales, y que la mayor dificultad relatada para su concretización fue con los profesionales de la categoría médica. Los resultados también demuestran que la colaboración entre los servicios, la universidad y la secretaría municipal de la salud es un importante punto de apoyo para la ejecución del matriciamiento. Sin embargo, aún son necesarias las inversiones en política en el municipio, que pueda fortificar el apoyo matricial, además de los espacios de educación permanente para los trabajadores. Para que pueda implementarse este orden organizacional, son necesarios la articulación y el trabajo colectivo de todos los actores que buscan la integralidad de la atención. Construir reflexiones sobre estas experiencias se convierte en algo esencial, problematizando el quehacer de los profesionales en esta área y reconociendo las dificultades y los avances.

Palabras clave: Salud Mental, Atención Primaria de Salud, Servicios de Salud, Salud Publica.

\section{INTRODUÇÃO}

Nas últimas três décadas, o campo da atenção psiquiátrica sofreu muitas críticas e passou por um intenso processo de reorganização e elaboração de novas propostas, processo este denominado reforma psiquiátrica ${ }^{1}$. Neste processo, demonstra-se a importância do fim do modelo psiquiátrico hospitalocêntrico, além de um inconformismo com a atenção prestada aos usuários com transtornos mentais.

O movimento da reforma foi demonstrando experiências exitosas, criando serviços abertos, que valorizavam a participação da família no processo de tratamento e superavam o modelo asilar hegemônico, transferindo o foco do tratamento hospitalar para uma rede de atenção psicossocial ${ }^{2}$.

Nesta perspectiva, os Centros de Atenção Psicossocial (CAPS) são considerados dispositivos de referência para a organização da rede de atenção em saúde mental. São substitutivos ao hospital 
psiquiátrico e devem respeitar a lógica da territorialização, ou seja, devem estar próximos da residência e dos espaços de convívio social (família, escola, trabalho, centro religioso, dentre outros) dos indivíduos que utilizam este serviço ${ }^{3}$.

No processo de integrar a saúde mental com a atenção primária na realidade brasileira, o modelo de Apoio Matricial (AM), ou matriciamento, tem sido o norteador de experiências implementadas em diversos municípios ao longo dos últimos anos. Criado em 1999 por Gastão W. Campos, o apoio matricial ou matriciamento pode ser definido como uma nova proposta que visa transformar a lógica tradicional dos sistemas de saúde: referências e contrarreferências, encaminhamentos e protocolos, sendo que os efeitos burocráticos e pouco dinâmicos podem vir a ser atenuados por ações horizontais que integrem os componentes e seus saberes nos diferentes níveis assistenciais ${ }^{4}$.

Segundo o documento do Ministério da Saúde, "O apoio matricial constitui um arranjo organizacional que visa outorgar suporte técnico em áreas específicas às equipes responsáveis pelo desenvolvimento de ações básicas de saúde para a população" (p.4). Ocorre assim uma parceria entre profissionais de referência e profissionais de apoio matricial.

A equipe ou profissional de referência são aqueles que têm a responsabilidade pela condução de um caso individual, familiar ou comunitário, na perspectiva de acompanhamento longitudinal com este conjunto de usuários. Já a equipe de apoio matricial é composta por especialistas que tem um conhecimento e um perfil diferente daquele dos profissionais de referência, mas que podem agregar conhecimentos e contribuir com intervenções que aumentem a resolubilidade de problemas de saúde da equipe de referência ${ }^{6}$.

O objetivo desta diretriz organizacional seria a criação de um modelo de atendimento mais singularizado, em que cada técnico (ou mini-equipe) teria uma clientela sob sua responsabilidade que seria mais ou menos fixa. Isto objetiva tanto "potencializar o papel terapêutico inerente à dialética de vínculo, quando bem trabalhada, como também permitir que os profissionais acompanhem melhor, no tempo, o processo saúde/enfermidade/intervenção de cada paciente" (p.397)7.

\section{Implementação do SUS em Santos - Saúde Mental e Atenção Básica}

O município de Santos (SP), no âmbito da Saúde Mental, é reconhecido por seu pioneirismo no processo de desinstitucionalização, com o fechamento do Hospital Psiquiátrico Casa de Saúde Anchieta e sua substituição por uma rede de serviços territoriais ${ }^{8}$.

Atualmente, Santos conta com uma rede de serviços de saúde mental com cinco serviços voltados ao atendimento de adultos, três serviços voltados à infância, um serviço de atendimento ao adolescente, um serviço de atendimento ao toxicodependente, um serviço de reabilitação social 
e um lar abrigado9. Os serviços de referência para a saúde mental para adultos em Santos são intitulados Núcleo de Atenção Psicossocial (NAPS) e atualmente se aproximam da definição de CAPS III, oferecendo atendimento $24 \mathrm{~h}$.

Já na Atenção Básica(AB) em Santos, as transformações geradas pelo modelo do SUS se deram principalmente com a criação das policlínicas, que são as unidades que compõe a rede descentralizada de serviços de saúde, com áreas de abrangência e responsabilidade definidas ${ }^{10}$.

De acordo com Valadão ${ }^{10}$, muitas são as dificuldades para tornar realidade a atenção integral à saúde nas policlínicas, inclusive devido à necessidade de reinventar o modelo de atenção e de vigilância, do risco de se reproduzir o modelo médico centrado e da resposta isolada e medicalizante aos problemas sentidos pela população.

Posteriormente, com a criação do Programa de Saúde da Família (PSF), que atualmente é denominado Estratégia de Saúde da Família (ESF), algumas dessas equipes passam a fazer parte da rede santista, mas ainda em menor escala.

Criada em 1994, a ESF tem sido priorizada como modelo de atenção à saúde em nível primário e teve estabelecidos objetivos, metas e indicadores específicos. A ESF tem sido apontada como modo de transformar o modelo de atenção à saúde tradicional, utilizando-se de estratégias como o trabalho multiprofissional, o investimento no vínculo com a população, o trabalho no território e o fortalecimento de ações de promoção de saúde e prevenção de doenças ${ }^{11}$.

No município de Santos a proposta de apoio matricial é recente e não foram encontrados estudos que tratassem desta experiência. A residência multiprofissional participou de algumas iniciativas de matriciamento por meio dos seus diferentes atores, tutores, preceptores e residentes, nos cenários em que atuavam. Assim, este trabalho visa tecer algumas reflexões sobre o Apoio Matricial sob a ótica de profissionais que atuam nos NAPS em Santos, identificando as potencialidades e os desafios relacionados com a sua prática junto às equipes apoiadas.

Considerando a complexidade envolvida e por ser uma das propostas de integralidade da atenção à saúde, as experiências do matriciamento em saúde mental precisam ser acompanhadas, já que propostas só se tornam efetivas se forem transformadas em práticas concretas que produzam impacto na qualidade de vida da população ${ }^{12}$.

\section{PERCURSO METODOLÓGICO}

O presente estudo tem como base a pesquisa qualitativa e descritiva. Segundo Minayo ${ }^{13}$, a pesquisa qualitativa busca compreender o universo dos significados, das motivações, das crenças e atitudes, sendo relacionados com processos e fenômenos não mensuráveis. 
Nogueira-Martins e Bógus ${ }^{14}$ afirmam que a abordagem qualitativa permite construir meios para que as ações dos serviços sejam delineadas pelo diálogo entre as distintas lógicas culturais onde os serviços estão inseridos, de modo que à medida que se compreende o objeto de estudo, transforma-se a realidade social, tornando as ações dos serviços de saúde e de seus agentes mais eficientes e eficazes.

Esta pesquisa foi desenvolvida no Programa de Residência Multiprofissional em Atenção à Saúde (PRMAS) da Universidade Federal de São Paulo - Campus Baixada Santista (UNIFESP/BS), iniciada em maio de 2014 e concluída em janeiro de 2015. Para operacionalização da pesquisa, esta foi dividida em três etapas principais, baseando-se no referencial teórico da Reforma Psiquiátrica Brasileira e da Política de Saúde Mental do SUS para a atenção básica.

Inicialmente, houve um levantamento bibliográfico sobre o tema abordado para embasamento teórico das discussões e contextualização do tema.

$\mathrm{Na}$ etapa seguinte, foi delineado que seriam realizadas entrevistas semiestruturadas com um trabalhador de cada NAPS de Santos que realize matriciamento em Saúde Mental nas UBS, considerando que há cinco NAPS na cidade. Esse modelo de entrevista semiestruturada permite aos matriciadores terem a liberdade de falar sobre suas impressões, dificuldades, potências, estratégias encontradas, dentre outros aspectos. O roteiro para a entrevista foi elaborado pelas pesquisadoras baseado nas leituras realizadas previamente sobre o tema.

Essa pesquisa foi orientada pelos princípios éticos da resolução 466/12 de 12/12/2012 do Conselho Nacional de Saúde. O presente estudo foi submetido e aprovado pela Comissão de Pesquisa e Intervenção da Secretaria Municipal de Saúde de Santos e pelo Comitê de Ética em Pesquisa em Seres Humanos da UNIFESP, por meio da Plataforma Brasil - segundo aprovação número CAAE: 31919314.4.0000.5505 e parecer 691.458/2014.

O Termo de Consentimento Livre e Esclarecido foi entregue e assinado por todos os entrevistados, após a leitura e compreensão dos aspectos da pesquisa. Devido ao pequeno número de entrevistados e visando garantir o anonimato, optou-se por não identificar as falas dos mesmos no decorrer da pesquisa.

Foram coletados dados de identificação dos trabalhadores, formação e tempo de trabalho no atual serviço. As questões da entrevista tratavam, principalmente, sobre qual o conceito que os profissionais têm sobre Apoio Matricial (AM), como esse se estrutura na unidade em que ele trabalha, quais são os casos que deveriam compor o AM, o quanto tem se conseguido corresponsabilizar as equipes das unidades básicas com relação ao matriciamento, se essa metodologia de trabalho é compreendida como importante e o que poderia ser potencializado nesse processo. 
As conversas foram gravadas com posterior transcrição das falas. A coleta de dados ocorreu de agosto a outubro de 2014 e as entrevistas foram transcritas até novembro do mesmo ano.

Os critérios de inclusão foram o aceite em participar da pesquisa e a disponibilidade de tempo para realização das entrevistas. Como sugere Minayo ${ }^{15}$, também foram critérios a proximidade do sujeito com o tema a ser discutido e a necessidade de estar envolvido em ações de matriciamento em saúde mental, ou seja, privilegiaram-se os sujeitos que detêm as informações e experiências que o pesquisador desejava conhecer, além da tentativa de formar um grupo de entrevistados em que o conjunto de informações colhidas pudesse ser diversificado, sendo para isso, privilegiados profissionais de diferentes categorias.

Por fim, na última etapa fez-se a análise dos dados encontrados utilizando o método de análise de conteúdo. De acordo com Moraes ${ }^{16}$, a análise de conteúdo é uma metodologia de pesquisa usada para interpretar o conteúdo dos textos a fim de atingir uma compreensão de seus significados para além de uma leitura comum.

Inserida na análise de conteúdo, optou-se por utilizar a análise temática. Segundo Moraes ${ }^{16}$, "quando uma pesquisa utilizando análise de conteúdo se dirige à questão para dizer o quê? o estudo se direciona para as características da mensagem propriamente dita, seu valor informacional, as palavras, os argumentos e as ideias nela expressos"(p. 11).

\section{RESULTADOS}

\section{Caracterização dos entrevistados}

Foram realizadas entrevistas com um profissional de cada NAPS de Santos, totalizando cinco entrevistados. Estes foram indicados pelas chefias de cada serviço, após contato prévio da pesquisadora e apresentação do projeto.

Todas entrevistadas eram do sexo feminino, havendo três terapeutas ocupacionais, uma enfermeira e uma psicóloga. O tempo de trabalho no NAPS atual em que é funcionária variou de 5 a 22 anos, sendo a média de 12,2 anos e desvio padrão 7,91.

\section{Definição de matriciamento}

Ao perguntar aos profissionais o que eles entendiam sobre a definição de matriciamento em saúde mental, foi citado a interlocução, principalmente com a atenção básica, mas uma das entrevistadas também citou a possibilidade de conversa com outros serviços especializados. 
“... então é aquela coisa de que o paciente possa ser visto nos vários olhares, né? Não sendo "Ah, ele é da rede básica" ou "Ah, ele é do NAPS". Ele é da rede. E tudo que fizer parte dessa rede tem que se comunicar. Então, pra mim, matriciamento seria esse contato, sendo como uma troca."

Outra questão relevante comentada se refere ao matriciamento como possibilidade de conversa entre diversos setores de forma a prevenir a medicalização do sofrimento.

"Então, eu vejo que, assim, o matriciamento em Saúde Mental aqui em Santos, primordialmente, é você poder abrir uma conversa, um diálogo com outros profissionais das outras unidades pra falar "Olha, vamos entender o que essa população tá fazendo, o que essas pessoas tão precisando, $[. .$.$] e como é que a gente pode lidar com isso sem tentar$ fazer esse risco [...] de medicalizar todo e qualquer sofrimento."

\section{Como o matriciamento está acontecendo em Santos}

Durante a pesquisa foi possível perceber que cada NAPS estabeleceu um fluxo diferente para que o matriciamento ocorresse. Em dois NAPS a equipe de técnicos inteira se compromete com o matriciamento e cada funcionário fica responsável por matriciar uma ou duas unidades básicas de saúde, considerando que as demandas de cada unidade são diferentes das demais.

\footnotetext{
“Cada técnico ficou responsável por uma UBS... uma ou duas, às vezes. [...] Então, cada técnico tá com uma UBS pra poder fazer essa reunião de matriciamento ou fazer outras ações, além da reunião."

"A gente dividiu um mini grupo pra cada policlínica, né? [...] porque, aí, os problemas daquela policlínica são muito específicos. É muito diferente uma da outra. Então, é pra tentar solucionar os problemas daquela população."
}

Já nos outros três NAPS poucas pessoas estão envolvidas no matriciamento, que acaba sendo efetivado apenas em algumas unidades de saúde. Além disso, um dos profissionais envolvidos comenta da sobrecarga de trabalho, pois não consegue atender toda a demanda.

\footnotetext{
“[...] algumas unidades conseguiram fazer um bom diálogo com algumas UBS. Então, a coisa ficou ali entre unidades - algumas conseguem, algumas fazem melhor e outras não. [...] Aí, por exemplo, a gente não tem pernas aqui no NAPS. Antes era eu e a diretora só que ficávamos com essa coisa e tem acho que oito policlínicas de referência nossa... Aí não tem condições, você não tem como."

“Então, hoje o que é que acontece é só com 'unidade X'. Então, a gente [...] atende treze bairros, mas a gente faz isso (matriciamento) só com essa'unidade $\mathrm{X}$ '
}

Foram relatadas diversas dificuldades de se estabelecer parcerias com as UBS, mas também com alguns funcionários do próprio NAPS. A categoria médica foi indicada como a mais resistente com relação ao matriciamento, apesar de alguns médicos participarem deste processo. Foi observado também a não valorização da equipe multiprofissional do NAPS para realizar os encaminhamentos ou escrever relatórios sobre os usuários.

“ [...] A gente mandava um relatório e voltava porque não era um relatório médico... e então, o médico falava assim: "Um relatório de T.O., de psicólogo não. Eu quero um relatório médico." 
"Todas as categorias poderiam participar, mas principalmente a classe médica, né? Que não, eh, praticamente não participam, assim. São bem resistentes, né? A gente tem um médico que conversa bem sobre isso, né? [...] Então, assim, são quatro médicos e só um participa"

\section{Como o matriciamento é compreendido na UBS}

A maioria dos profissionais alega que o matriciamento parece não ser bem compreendido nas unidades básicas, mas que naquelas em que se estabeleceram parcerias e já houve discussões de casos há um entendimento melhor da proposta.

"[...] eu acho que nesse momento ainda é compreendido como uma tarefa a mais pra eles. Eh, "vamos atender uma população que não atendíamos antes", acho que tem esse entendimento, de que são pessoas diferentes que vão chegar lá para serem atendidas, né?"

“As pessoas não entendem ainda, eh, principalmente, as pessoas que não participam dessas reuniões sistemáticas que a gente tem. [...] ainda precisa o tempo inteiro, acho que a gente tá falando."

Os matriciadores percebem que nas unidades em que existe ESF o contato e as discussões são facilitadas. Alguns apontam o fato da existência de reuniões periódicas já estabelecidas, outros uma maior disponibilidade por parte dos profissionais, além de sua maior proximidade com algumas propostas do matriciamento que são comuns a ESF como a prática no território.

“[...] a policlínica não tem reunião como o PSF tem. Então, é aquela coisa que o cara entra no consultório, atende, atende, atende e tchau, até amanhã"

“A gente conseguiu porque era um PSF, e é mais fácil trabalhar com um PSF, porque os médicos generalistas já entendem um pouco mais. Eles já têm essa visão de trabalhar no território, né? [...]."

Outro fator que tem sido apontado como facilitador das relações entre a Atenção Básica e a Saúde Mental são alguns projetos da Universidade, no caso a UNIFESP - Campus Baixada Santista, como a Residência Multiprofissional em Atenção à Saúde, a especialização em Formação e Cuidado em Rede e o Programa de Educação pelo Trabalho para a Saúde (PET - Saúde) Saúde Mental.

\footnotetext{
"Eh, mesmo assim, eu acredito que o que a gente tá fazendo aqui[...] tá muito legal e tá muito além do que a gente pensava que ia conseguir. Eu sei que isso é em função da participação da residência e do PET [...], mas eu entendo que tá sendo super interessante poder, eh, experimentar esse tipo de ação aqui dentro. Onde a gente consegue hoje falar, eh, quase que a mesma língua, duas equipes, né? [...] é uma das experiências mais interessantes que eu pude participar."
}

Com o envolvimento da universidade dessas diferentes formas, os matriciadores notam mudanças positivas no modo de alguns trabalhadores da $\mathrm{AB}$ compreenderem o apoio matricial, mas também notam a possibilidade de oferecer um cuidado mais integral ao usuário.

Ao mesmo tempo em que visualizam a universidade como um apoio importante, também ISSN 1982-8829 Tempus, actas de saúde colet, Brasília, 11(3), 85-103, 2017 - Epub mar, 2018 
demonstram certa incerteza com relação à continuidade do trabalho atual quando esses projetos forem encerrados.

“[...] eu tenho todas as minhas funções no NAPS e também cuido do matriciamento. Então, tem coisas, às vezes, que não dá [...]. A hora que acabar o PET eu não sei se eu vou ter essa disponibilidade de sair no meu horário de trabalho."

\section{O matriciamento como estratégia de trabalho}

Todos os entrevistados afirmam que concordam com o matriciamento como estratégia de trabalho, mas percebem que a prática está ainda muito distanciada da teoria no município. Afirmam vislumbrar as potencialidades desse processo, mas também utilizam expressões como "processo artesanal" e "freio de mão puxado" para falar sobre como o processo ainda se encontra muito mais ligado a pessoas do que aos serviços, não havendo uma política clara sobre esta questão.

\footnotetext{
"Eh, o processo lá é feito bem artesanal assim. É bem cuidadoso. [...] Então, assim, só que isso é bem lento, a gente não consegue ter uma produção numérica consistente ainda, porque é só um bairro, e hoje a gente tem só um médico parceiro nosso. [...] Hoje eu acho muito pequeno, assim, [...] BEM freio de mão puxado, sabe?"
}

Uma das entrevistadas fala sobre as diferenças de fluxos estabelecidos nos NAPS com as UBS, e como os profissionais e serviços se sentem sem um referencial devido à falta de discussão e de estabelecimento de objetivos comuns a todos.

“Tem umas (UBS) que NEM TEM (matriciamento)... É isso que eu tô falando. [...] Elas tão ainda desniveladas, no sentido assim, é como se tivessem aberto uma corrida e aí cada um correu com as pernas que tem, entendeu? [...] Então, uns pararam, outros continuaram $[\ldots] . "$

Desta forma, os profissionais indicam algumas das questões que consideram essenciais para que o matriciamento possa se fortalecer no município, como uma construção conjunta pautada em discussões constantes, momentos de escuta para o sofrimento dos trabalhadores, sensibilizações para os médicos, em um processo contínuo que vai se aprimorando.

\footnotetext{
“Acho que tem que ser feito de tempo em tempo, né? Envolvendo os médicos. Não sei... Um aprimoramento, algumas coisas falando sobre o que o Ministério da Saúde preconiza [...]."

"Porque quando a gente fala matriciamento eu tenho assim... questões assim que a gente precisaria sentar no Município e perceber e discutir DE QUE matriciamento a gente vai falar. Porque tem várias formas de matriciar, né?"

"Então, assim, você discutir o tempo inteiro as questões que passam no trabalho, você discutir, eh... escutar o sofrimento daqueles trabalhadores, escutar as dificuldades. [...] Acho que você tem que realimentar as pessoas o tempo inteiro."
}

\section{CATEGORIAS TEMÁTICAS E DISCUSSÃO}

Depois de repetidas leituras, foram criadas três categorias de análise a partir de temas extraídos 
nas respostas dos entrevistados. Os temas encontrados foram a relação com a universidade, a atuação do médico e a falta de investimento político no matriciamento em Santos.

\section{Relação com a universidade}

Fica claro nos depoimentos que a universidade foi e ainda é um importante ponto de apoio para a efetivação do matriciamento no município. No caso das entrevistadas, a universidade é representada por diferentes projetos da UNIFESP - Campus Baixada Santista, sendo eles a Residência Multiprofissional em Atenção à Saúde, a especialização em Formação e cuidado em rede e o Programa de Educação pelo Trabalho para a Saúde (PET - Saúde) Saúde Mental.

A Residência Multiprofissional é definida como modalidade de ensino de pós-graduação lato sensu com carga horária de 60 horas semanais e duração de dois anos. A carga horária é dividida entre experiências teóricas e práticas, enfatizando a formação em serviço e destinado às categorias profissionais que integram a área da saúde, excetuada a médica. No caso do programa de Residência Multiprofissional em Atenção à Saúde, os residentes atuam na atenção básica e hospitalar, sendo a equipe formada por profissionais de Terapia Ocupacional, Fisioterapia, Serviço Social, Educação Física, Psicologia, Enfermagem e Nutrição.

Uma das matriciadoras, que possui uma longa experiência na Saúde Mental em Santos, conta que a experiência do matriciamento é recente e que iniciou-se junto com uma proposta da residência. Afirma que alguns alunos ficavam em unidades básicas e outros nos NAPS, e que iniciouse um levantamento de casos leves que estavam no NAPS e que poderiam ser atendidos na atenção básica, segundo alguns critérios predefinidos. Após este momento inicial, os residentes continuam surgindo nos depoimentos como atores importantes para gerar ações concretas e reflexões junto às equipes, fator atribuído, entre outros aspectos, à extensa carga horária semanal em serviço.

Em seu trabalho de conclusão de curso, Moraes ${ }^{17}$ conta sobre o processo de aproximação da Secretaria de Saúde de Santos, por meio da coordenadoria de Saúde Mental, com a residência multiprofissional. Relata que a residência participou de um processo de inserção da saúde mental na atenção primária na região dos morros no período de 2010 a 2012, e que este processo gerou a aproximação dos dois serviços. "Quando os serviços estreitam suas relações, o cuidado compartilhado parece mais possível, ao passo que um serviço começa a se apropriar da rotina do outro" (p.24).

Moraes ${ }^{17}$ também enfatiza o papel da residência na educação permanente, pois contribuiu tecnicamente com os profissionais em relação ao cuidado integral dos usuários da Saúde Mental. Essa contribuição da equipe multiprofissional ocorreu em diversos espaços como em visitas domiciliares, grupos de Promoção de Saúde e no acolhimento da população na Unidade de Saúde.

Outro programa citado foi o PET, que é destinado a fomentar grupos de aprendizagem tutorial no âmbito da Estratégia Saúde da Família, viabilizando programas de aperfeiçoamento e 
especialização em serviço dos profissionais da Saúde, bem como de iniciação ao trabalho, estágios e vivências dirigidos aos estudantes de graduação da área. Cada grupo PET-Saúde é formado por um tutor acadêmico, trinta estudantes e seis preceptores ${ }^{18}$. No programa PET Saúde Mental da UNIFESP os alunos atuavam tanto nos NAPS quanto nas unidades básicas.

O PET é citado em diversas entrevistas como importante para o matriciamento, pois os alunos viabilizaram o levantamento de prontuários de casos leves do NAPS e deram início a ações práticas envolvendo discussões entre profissionais da atenção básica e da saúde mental, além de acompanhamento de usuários. Alguns profissionais do NAPS afirmam que como são preceptores do PET acabam tendo uma disponibilidade maior para se dedicarem ao matriciamento, e que os alunos colaboram no sentido de fazer reflexões, atendimentos e, às vezes, até serem porta-voz de informações entre equipes.

Já a especialização "Formação e Cuidado em Rede" foi realizada em parceria com a Secretaria Municipal de Saúde de Santos (SMS), com duração de um ano e carga horária de 362h. O curso contou com a participação de profissionais da rede (preceptores) envolvidos com o ensino de estudantes dos primeiros anos da graduação, de estágios e residência, e o aprendizado foi orientado por questões que surgiram a partir das experiências profissionais dos participantes. Este projeto visou ampliar a articulação ensino-serviço para a estruturação de processos de formação e de cuidado na rede da SMS, contribuindo para a construção da integralidade, além de possibilitar o encontro entre professores e profissionais de diferentes serviços no desafio de construir redes de cuidado à saúde ${ }^{19}$.

A especialização foi citada como local de aprendizagem, qualificação, discussão e como espaço que permitia que profissionais de diferentes serviços se conhecessem e pudessem trocar experiências práticas. De acordo com uma das entrevistadas, esses encontros facilitaram o contato posterior entre os profissionais na articulação da rede de saúde, permitindo que parcerias, antes inexistentes, pudessem se estabelecer para o matriciamento.

Destaca-se, assim, o papel da universidade como instituição que forma os alunos para uma prática mais próxima do serviço, mas que também se destaca como possibilidade de promoção de uma Educação Permanente para os profissionais que já atuam na saúde.

Para $\mathrm{Ceccim}^{20}$, as práticas de Educação Permanente devem partir das necessidades vividas pelos trabalhadores, sendo mais do que apenas uma palestra ou um simples repassar de informação. É importante que os profissionais percebam que a maneira vigente de agir ou pensar é insuficiente para dar conta dos desafios do trabalho, pois só assim estarão dispostos a produzir alternativas práticas e de conceitos capazes de gerar transformações.

Sendo assim, talvez seja necessário modificar a maneira como as formações em serviço são 
pensadas, de modo a discutir com os trabalhadores os reais incômodos que vivenciam na prática, mostrando que eles são protagonistas e agentes de mudanças, para que estes possam sair do papel de meros depositários de informações.

A parceria entre a universidade, a rede de gestão política e de atenção à saúde mostra-se como potente para implementar novos processos de educação ${ }^{21}$. Ao mesmo tempo, deve-se problematizar constantemente a questão da continuidade dos programas relacionados com a universidade, já que se criam demandas nos serviços que muitas vezes acabam por ficar sem continuidade após o término do período dos projetos vigentes. Por isso, deve-se trabalhar também com o horizonte de que as equipes de saúde se tornem cada vez mais apropriadas da questão do matriciamento e mais fortalecidas com a determinação de políticas que invistam neste processo.

\section{Sobre a atuação dos profissionais médicos}

Nos relatos das entrevistadas, a atuação do profissional médico surgiu como um dos problemas mais significativos para que algumas ações do matriciamento não se concretizem. Estas apontam a dificuldade de acessar os médicos tanto na atenção básica quanto no próprio NAPS, alegando que conseguem a colaboração de uma minoria de profissionais para o processo de AM.

Dentre algumas das dificuldades citadas, surge a questão da categoria profissional - quando o médico apenas aceita o encaminhamento de outro médico. Essa ação pode representar algumas características de formação, na qual a universidade moderna foi

configurada em disciplinas e departamentos, dando origem ao corporativismo das especialidades e aos controles burocráticos que dificultam as práticas interdisciplinares. Profissionais e associações disciplinares passaram a defender a vigência e manutenção dessa perspectiva, aceitando a fragmentação como modo organizador dos saberes e fazeres (p.149) ${ }^{22}$

Apesar da existência de novas tendências na formação em saúde, esse modo de ensinar, pautado em fragmentações e especialidades, ainda pode ser notado em muitas universidades, formando profissionais que chegam ao serviço sem experiências de atuação em equipe, valorizando apenas o conhecimento de profissionais da mesma categoria.

Além disso, segundo Domitti ${ }^{6}$, as organizações de saúde têm a tradição de funcionar com um poder concentrado em diretores, médicos e especialistas. Esse poder concentrado pode ser observado na organização de serviços de saúde, que ainda atuam baseados no modelo médico hegemônico, priorizando o saber e a pessoa do médico.

Observando estes fatores pode se dizer que prevalece, no atual modo de produção de saúde, o uso de tecnologias duras (as que estão inscritas em máquinas e instrumentos), em detrimento de tecnologias leve-duras (definidas pelo conhecimento técnico) e leves (as tecnologias das relações entre os sujeitos produzidas em ato) para o cuidado ao usuário ${ }^{23}$.

ISSN 1982-8829 Tempus, actas de saúde colet, Brasília, 11(3), 85-103, 2017 - Epub mar, 2018 
Deste modo, para que o serviço seja produtor do cuidado centrado no usuário e não em procedimentos, é necessária uma inversão das tecnologias de cuidado a serem utilizadas na produção da saúde, enfatizando o uso de tecnologias leves e leve-duras ${ }^{24}$.

Estes dados dizem de uma dificuldade com o profissional da categoria médica, mas também refletem nos demais profissionais que formam as equipes de saúde, pois estes também estão inseridos nesta realidade de trabalho e acabam por reproduzir, muitas vezes, esse modelo médico centrado.

Apesar das iniciativas do Ministério da Saúde e de diversos atores em propor a aproximação entre a atenção básica e o NAPS, este processo tem encontrado dificuldades relacionadas com as particularidades do campo da Saúde Mental. Propõe-se um novo modo de conceber a relação do profissional com a população e com a questão do processo de saúde-doença, mudanças estas que não são simples para os profissionais, pois implicam em transformações que afetam desde as concepções pessoais, até questões de organização dos serviços e de políticas mais amplas ${ }^{11}$.

Campos e Gama ${ }^{11}$ afirmam que é comum encontrar equipes cindidas, uma parte trabalhando os problemas físicos e a outra responsável pelos problemas psíquicos. As práticas de saúde mental na atenção básica ainda estão muito vinculadas ao modelo biomédico, faltando preparo aos profissionais e havendo grande dificuldade de implantação do que é preconizado pelas políticas públicas.

Mesmo assim, diversas pesquisas apontam que as equipes reconhecem mudanças positivas após a implementação do AM, mesmo que este não ocorra exatamente como indica a teoria ou as políticas. Numa pesquisa realizada em Campinas com trabalhadores da saúde mental, das equipes de referência da atenção básica e com gestores, estes percebem que foram facilitadas algumas discussões sobre a impossibilidade de se separar a "saúde mental" da "saúde geral" e que foram potencializadas as ações das equipes de referência nos casos em que se expressam a subjetividade e o sofrimento. Percebem, também, que a reflexão sobre as necessidades singulares das pessoas atendidas e a construção conjunta de projetos terapêuticos favorece a corresponsabilização e a avaliação contínua do tratamento, gerando benefícios para as pessoas atendidas e para a equipe, que consegue visualizar resultados ${ }^{6}$.

As matriciadoras entrevistadas também relatam que apesar das dificuldades, percebem benefícios nos locais nos quais conseguem realizar o matriciamento, notando mudanças no modo de acompanhamento ao usuário e também transformações em si mesmas e nos demais trabalhadores de saúde. Neste processo, contam com o apoio de alguns médicos, o que mostra que alguns profissionais já estão sensibilizados com a questão do AM. Talvez esses médicos possam ser, em conjunto com outros profissionais matriciadores e com a criação de políticas mais específicas sobre esta questão no município, potencializadores de trocas de experiências pautadas em vivências 
práticas que têm sido exitosas.

Deve-se enfatizar, também, que novas medidas vêm sendo tomadas para a mudança desse panorama, como a resolução n. ${ }^{\circ} 3$ do ministério da educação que institui diretrizes curriculares nacionais do curso de graduação em Medicina e afirma que os alunos terão formação em Atenção à Saúde, Gestão em Saúde e Educação em Saúde ${ }^{25}$.

\footnotetext{
O graduado em Medicina terá formação geral, humanista, crítica, reflexiva e ética, com capacidade para atuar nos diferentes níveis de atenção à saúde, com ações de promoção, prevenção, recuperação e reabilitação da saúde, nos âmbitos individual e coletivo, com responsabilidade social e compromisso com a defesa da cidadania, da dignidade humana, da saúde integral do ser humano e tendo como transversalidade em sua prática, sempre, a determinação social do processo de saúde e doença (p. 1$)^{25}$.
}

Estas são algumas das muitas reflexões possíveis sobre os processos de trabalho e a atuação dos profissionais médicos. Enfatiza-se, entretanto, que nenhum profissional desta categoria se candidatou ao estudo e que, deste modo, não foi possível ouvir a opinião destes profissionais sobre o assunto. Esta realidade deve ser investigada de modo a se aproximar das dificuldades apresentadas por estes profissionais no processo de AM, a fim de se discutir e procurar propostas que permitam que os fluxos de trabalho possam ser estabelecidos e que esta estratégia possa se concretizar.

\section{Falta de investimento político no matriciamento em Santos}

A pesquisa encontrou a falta de investimento político no município como uma das principais dificuldades relatadas para a consolidação do matriciamento.

Os profissionais mais antigos no serviço citam que em 2011 houve investimentos importantes para se pensar o início do matriciamento em Santos, no qual muitos profissionais se envolveram. Porém, com o passar do tempo, algumas pessoas foram se afastando desta proposta, acontecimento que os profissionais entrevistados atribuem a falta de uma determinação clara e de discussões sobre a consolidação deste matriciamento na prática, além de outros fatores.

Quando questionadas sobre o que proporiam se estivessem construindo o matriciamento para Santos surgiram propostas de momentos de escuta para sofrimento dos trabalhadores, momentos de trocas de experiência entre os trabalhadores dos NAPS, sensibilizações para os médicos e melhor apropriação dos recursos oferecidos no território. Alguns profissionais também sugeriram que houvesse profissionais de saúde mental fixos nas unidades básicas.

Percebe-se que não há consenso sobre como deve ser implantado o matriciamento, mas uma das entrevistadas relata que um ponto relevante é a discussão com todos os envolvidos sobre a definição de matriciamento e compreensão da proposta política deste modo de trabalho. Também foi citado que deve ser discutido que tipo de matriciamento seria mais adequado para ser implantado 
no município, já que ela acredita que existem diversas formas de se organizar para concretizar o AM. Além disso, surgiram ideias relacionadas com a importância de se ter momentos de troca de experiência e reflexão contínua sobre a prática, já que este é um processo novo que gera frustrações e dúvidas.

Para os matriciadores, a estratégia de AM vem de encontro com a necessidade percebida nos NAPS de se atentar para a demanda de casos graves e persistentes do município, que são a população principal deste tipo de equipamento, mas que não conseguem ser acessados devido ao excesso de demanda de casos leves existente.

Em uma pesquisa realizada em Campinas sobre a organização das ações de saúde na atenção básica a partir da implantação do Apoio Matricial26, os profissionais de saúde mental também afirmam que sua principal demanda de atendimento são os casos leves e avaliam que o AM pode ajudar a aumentar a capacidade resolutiva das equipes de referência e favorecer o atendimento de casos graves.

Este dado também aparece na pesquisa de Gonzaga ${ }^{9}$, que realizou entrevistas com trabalhadores dos NAPS de Santos para investigar sobre a inversão de prioridades na atenção aos usuários deste serviço. Em seu trabalho, Gonzaga afirma que a grande dificuldade de atendimento é a demanda excessiva dos casos leves, "que geram novas necessidades para o serviço e, consequentemente, dificultam a atenção dos profissionais para os pacientes realmente graves, que necessitam de uma assistência mais intensiva, próxima e constante" (p. 72). Essa pesquisa enfatiza ainda a lacuna existente entre a prática dos serviços e o que é preconizado pelo Ministério, já que o enfoque dos CAPS III seria para atendimentos de casos severos e persistentes.

Campos e Gama ${ }^{11}$ apontam que para os usuários portadores de Transtorno Mental Severo e Persistente já existe uma política eficaz em andamento, mas que poucas são as possibilidades de cuidado para os transtornos mentais menos graves, nos quais há a ausência de uma política mais efetiva e o desafio de se construir uma rede de assistência que consiga dar suporte para estes casos.

Desta forma, o matriciamento pode ser um caminho para a redistribuição do fluxo dos usuários na rede de saúde mental de Santos, colaborando para uma discussão mais próxima entre as equipes da Saúde Mental e da $\mathrm{AB}$ de forma a favorecer o atendimento ampliado na $\mathrm{AB}$ e a diminuição de encaminhamentos equivocados de casos para a especialidade ${ }^{27,9}$.

Porém, este processo de implantação do matriciamento não é simples e implica na construção de uma proposta que se adeque à realidade do município, sem perder, contudo, as diretrizes propostas pela política já existente.

Para produzir mudanças de práticas de gestão e de atenção, é fundamental que sejamos capazes de dialogar com as práticas e concepções vigentes, que sejamos capazes de 
problematizá-las - não em abstrato, mas no concreto do trabalho de cada equipe - e de construir novos pactos de convivência e práticas, que aproximem os serviços de saúde dos conceitos da atenção integral, humanizada e de qualidade, da eqüidade e dos demais marcos dos processos de reforma do sistema brasileiro de saúde [...] (p.165) ${ }^{20}$

Essas mudanças fazem parte de um processo que precisa ser bem articulado, para que o matriciamento não se torne apenas um modo de inverter os encaminhamentos da Saúde mental para a Atenção Básica. Deve-se retomar que o matriciamento envolve a corresponsabilização de ambas as equipes pelos casos, de forma a se estabelecerem relações horizontais que favoreçam a discussão de casos, a construção de Projetos Terapêuticos Singulares visando a autonomia dos usuários, dentre outros aspectos.

Ao mesmo tempo, deve-se reconhecer também que este não é um processo simples, e implica em uma mudança significativa nos modos de pensar e agir de todos os profissionais envolvidos.

\footnotetext{
Devemos reconhecer que a mudança da lógica de trabalho proposta pelo Apoio Matricial não é fácil de ser assumida pelas equipes e não ocorre automaticamente. Ela deve ser especificamente trabalhada junto às equipes, instalando-se espaços destinados à reflexão crítica sobre o próprio trabalho, e que possam ser continentes aos problemas na relação entre a equipe, aos preconceitos em relação à loucura, à dificuldade de entrar em contato com o sofrimento do outro e à sobrecarga trazida pela lida diária com a pobreza e a violência(p.137) $)^{26}$
}

Além deste fator, a pesquisa mostra que a falta de determinação de uma política clara no município e o não investimento em propostas de educação permanente desestimulam os trabalhadores e dificultam os processos de trabalho, sendo considerados fatores essenciais para o AM. São necessários espaços de reflexão e formação permanentes para que os trabalhadores consigam processar todas as questões complexas que envolvem o AM e sejam ao mesmo tempo capazes de realimentar a potencialidade que este modelo de organização tem enquanto arranjo transformador das práticas hegemônicas na saúde ${ }^{26}$.

\section{CONSIDERAÇÕES FINAIS}

Diante das discussões que foram realizadas ao longo deste estudo, pode-se compreender um pouco melhor sobre como o apoio matricial está ocorrendo em Santos, a partir da perspectiva de matriciadores. É possível perceber que este processo ainda é recente no município e que precisa ser melhor compreendido pelos atores envolvidos, para que possa realmente ser efetivado.

Sugere-se a relevância de pesquisas que possam dar voz aos outros profissionais envolvidos no matriciamento, como os trabalhadores da atenção básica, os gestores e até outras categorias profissionais que atuam na especialidade. Compreender os diversos pontos de vista e as dificuldades e impasses envolvidos neste processo podem ser fundamentais para que o apoio matricial realizado no município possa se aproximar, cada vez mais, do modelo teórico e do que é preconizado na 
política.

Construir reflexões sobre estas experiências torna-se essencial, problematizando o fazer dos profissionais neste campo e reconhecendo as dificuldades e os avanços.

$\mathrm{Na}$ pesquisa realizada, percebeu-se que o matriciamento não ocorre da mesma forma nas diversas unidades de saúde e que em algumas unidades básicas ainda não foi possível iniciar este processo.

O apoio matricial demanda uma série de condições de organização do serviço e do processo de trabalho, de agenda, de fluxos e de disponibilidades pessoais e institucionais dos profissionais envolvidos para se tornar possível.

Como o serviço de saúde está centrado tradicionalmente no médico e na produção de procedimentos, é um desafio produzir um cuidado integral centrado nos usuários dos serviços e em seus processos de saúde-doença. Mas, para além do profissional médico, observa-se uma dificuldade dos profissionais da atenção básica em se aproximar do sofrimento psíquico da população e de sua subjetividade, ao mesmo tempo em que a Saúde Mental tem que extrapolar sua atenção da especificidade para a integração com a atenção básica.

Neste processo, a universidade se mostra como importante articulador e apoiador de processos instituídos em parceria com a secretaria de saúde e com os serviços. Esta é responsável por projetos que se desenvolvem no cotidiano dos serviços e que, portanto, colabora para alguns processos de transformação. Além destes projetos, a universidade pode colaborar em processos de Educação Permanente para os funcionários do serviço, tornando-se parceira na elaboração de discussões e reflexões que incentivem a problematização dos desafios do cotidiano de trabalho, em busca de uma atenção integral ao usuário.

Assim, é necessário também investir na criação de políticas que sejam claras e que embasem os profissionais para sua prática. Mesmo com os conhecidos limites de recursos humanos, a existência de excessivas demandas na atenção básica e na especialidade, a burocratização, dentre outros, é preciso investir nos processos e lógicas de trabalho que fortalecem a maior resolutividade dos problemas de saúde da população e oferecem um cuidado mais próximo ${ }^{20}$.

Fica claro que muito há de ser trabalhado ainda, mas deve-se evidenciar que já houve alguns investimentos e discussões sobre este processo no município que não devem ser esquecidos. E é exatamente esse o desafio: inventar uma nova realidade de cuidado que não despreze o caminho que já começou a ser traçado.

Acredita-se que o matriciamento pode colaborar para a reformulação de fluxos de atendimento entre a Saúde Mental e a Atenção Básica, possibilitando o atendimento adequado da população com quadros graves de sofrimento psíquico no NAPS e um atendimento mais singular, qualificado e integral aos demais casos. Além disso, permite-se que a pessoa com algum sofrimento psíquico não seja simplesmente rotulada e encaminhada para a especialidade, pois a atenção básica 
poderá realizar o acolhimento e escuta do sofrimento, solicitando colaboração da especialidade em atos menos automáticos e mais apropriados.

\section{REFERÊNCIAS BIBLIOGRÁFICAS}

1. Nicácio MFS. Utopia da realidade: contribuições da desinstitucionalização para a invenção de serviços de saúde mental. Campinas. Tese [Doutorado em Saúde Coletiva] - Faculdade de Ciências Médicas da Universidade Estadual de Campinas; 2003.

2. Morais APP. Saúde Mental na Atenção Básica: o desafio da implementação do apoio matricial. São Paulo. Tese [Doutorado em Saúde Pública] - Faculdade de Saúde Pública da Universidade de São Paulo; 2010.

3. Ministério da Saúde (Brasil). Secretaria de Atenção à Saúde. Departamento de Ações Programáticas Estratégicas.Saúde mental no SUS: os centros de atenção psicossocial. Brasília (DF): Ministério da Saúde; 2004. 86p.

4. Chiaverini DH (org.), Gonçalves DA, Ballester D, Tófoli LF, Chazan LF, Almeida Net al.Guia prático de matriciamento em Saúde Mental. Brasília (DF): Centro de Estudo e Pesquisa em Saúde Coletiva; 2011. 236p.

5. Ministério da Saúde (Brasil). Secretaria de Atenção à Saúde. Departamento de Ações Programáticas Estratégicas. Saúde Mental e Atenção Básica: o vínculo e o diálogo necessários. Brasília (DF): Ministério da Saúde; 2007. 7p.[citado em: 25 de Fev 2017]Disponível em: https://www.nescon. medicina.ufmg.br/biblioteca/imagem/1734.pdf

6. Domitti ACP. Um possível diálogo com a teoria a partir das práticas de apoio especializado matricial na atenção básica de saúde. Campinas.Tese [Doutorado em Saúde Coletiva] -Faculdade de Ciências Médicas da Universidade Estadual de Campinas; 2006.

7. Campos GWS. Equipes de referência e apoio especializado matricial: um ensaio sobre a reorganização do trabalho em saúde. Ciência \& Saúde Coletiva [Internet]. 1999 [citado em 20 de Fev 2017]; 4(2): 393-403. Disponível em:http://www.scielo.br/scielo.php?script=sci arttext\&pid=S141381231999000200013\&lng=en. http://dx.doi.org/10.1590/S1413-81231999000200013.

8.

Amarante PDC. Saúde Mental, desinstitucionalização e novas estratégias de cuidado. In: GiovanellaL, Escorel S, Lobato LVC, Noronha JC, Carvalho AI (org.). Políticas e Sistemas de Saúde no Brasil. 2 reimpressão. Rio de Janeiro: Ed. Fiocruz; 2011. p. 735 - 59.

9. Gonzaga NAN.Os significados dos encaminhamentos feitos aos CAPS III: a visão dos profissionais. Santos. Dissertação [Mestrado em Ciências da Saúde] - Universidade Federal de São Paulo; 2012.

10. Valadão MM. Policlínicas. In: Campos FCB, Henriques CMP (orgs.) Contra a maré à beira mar: A experiência do SUS em Santos. 2ed. São Paulo: Hucitec; 1997. p.113 - 116.

11. Campos RO, Gama C. Saúde Mental na atenção básica. In: Campos GWS, Guerreiro AVP (orgs.) Manual de práticas de atenção básica - saúde ampliada e compartilhada. 2ed. São Paulo: Aderaldo \&Rothschild; 2010. p. 221 - 246.

12. Oliveira FRL. A integração das ações no campo da Saúde Mental entre a Estratégia de Saúde da família e o Núcleo de apoio à Saúde da Família: desafios para uma prática interdisciplinar. São Paulo. Dissertação [Mestrado em Psicologia] - Instituto de Psicologia da Universidade de São Paulo; 2013.

13. Minayo MCS(org.),Deslandes SF, Gomes R. Pesquisa social: teoria, método e criatividade. 31 ed. Petrópolis: Vozes; 2012.

14. Nogueira-Martins MCF; BógusCM. Considerações sobre a metodologia qualitativa como recurso para o estudo das ações de humanização em saúde. Saúde e Sociedade [Internet]. 2004 Dez [citado em 20 Fev 2017]; 13(3):44-57. Disponível em: Availablefrom: http://www.scielo.br/scielo. php?script=sci_arttext\&pid=S0104-12902004000300006\&lng=en. http://dx.doi.org/10.1590/S010412902004000300006. 
15. MinayoMCS. O desafio do conhecimento: pesquisa qualitativa em Saúde. 12Ed. São Paulo: Hucitec; 2010. p. 189 - 200.

16. Moraes R. Análise de conteúdo. Revista Educação [Internet]. 1999 [citado em 23 Fev 2017]; 22

937): 7-32. Disponível em: https://pt.scribd.com/doc/90142519/ANALISE-DE-CONTEUDO

17. Moraes EMR. Residência Multiprofissional e a Saúde Mental: tecendo redes em Santos. Santos. Trabalho de Conclusão de Curso [Pós-graduação em atenção à saúde] - Universidade Federal de São Paulo - Campus Baixada Santista; 2012.

18. Ministério da Saúde (Brasil). Secretaria de Gestão do Trabalho e da Educação na Saúde. Portaria n. 1802, de 26 de agosto de 2008. Institui o Programa de Educação pelo Trabalho para a Saúde PET - Saúde. 2008.

19. Maximino VS.Curso de especialização em formação e cuidado em rede. 2013.

20. Ceccim RB. Educação permanente em saúde: desafio ambicioso e necessário. Interface Comunicação, Saúde, Educação [Internet]. 2005 Fev [citado em 20 Fev 2017]; 9(16): 161-178. Disponível em: http:/www.escoladesaude.pr.gov.br/arquivos/File/textos\%20eps/educacaopermanente.pdf

21. Vasconcelos ACF, Stedefeldt E, Frutuoso MFP. Uma experiência de intregação ensinoserviço e a mudança de práticas profissionais: com a palavra os profissionais de saúde. Interface (Botucatu) [Internet]. 2016 [citado em 25 Fev 2017]; 20(56):147-58. Disponível em: http://www.redalyc.org/articulo. oa? id=180142937013

22. Carvalho YM; Ceccim RB. Formação e Educação em Saúde: aprendizados com a Saúde Coletiva. In: Campos GWS, Carvalho YM,Minayo MCS,DrumondJM, Akerman M. Tratado de saúde coletiva. Rio de Janeiro: Hucitec; 2006. p. 149 - 182.

23. Merhy EE. Um ensaio sobre o médico e suas valises tecnológicas contribuições para compreender as reestruturações produtivas do setor Saúde. Interface - Comunicação, Saúde, Educação [Internet].2000 Fev [citado em 24 Fev 2017]; 4(6): 109- 116. Disponível em: http://www.redalyc.org/ articulo.oa? id=180114089009

24. Franco TB, Junior HMM. Integralidade na assistência à saúde: a organização das linhas do cuidado. In: Merhy EE, Magalhães Júnior HM, Rimoli J, Franco TB, Bueno WS (orgs.). O Trabalho em Saúde: olhando e experienciando o SUS no cotidiano. 2 ed. São Paulo: Hucitec. 2004.p. 125-133.

25. Ministério da Educação(Brasil). Conselho Nacional de Educação. Resolução nº 3, de 20 de junho de 2014. Institui Diretrizes Curriculares Nacionais do Curso de Graduação em Medicina e dá outras providências.2014. 14p. [citado em: 25 de Fev 2017]. Disponível em: http://biblioteca.participa.br/jspui/ bitstream/11451/949/1/rces003_14.pdf

26. Figueiredo MD; Campos RO. Saúde Mental na atenção básicaà saúde de Campinas, SP: uma rede ou um emaranhado? Ciência e Saúde Coletiva [Internet]. 2009 Fev[citado em 24 Fev 2017]; 14(1):129 - 138. Disponivel em: http://www.scielo.br/scielo.php?pid=S1413-81232009000100018\&script=sci abstract\&tlng=pt

27. Campos GWS; Domitti AC. Apoio matricial e equipe de referência: uma metodologia para gestão do trabalho interdisciplinar em saúde. Cad. Saúde Pública [Internet]. 2007Fev[citado em 25 Fev 2017]; 23(2):399-407. Disponível em: http://www.observasmjc.uff.br/psm/uploads/Apoio_matricial_e_ equipe_de_refer $\% \mathrm{C} 3 \% \mathrm{AAncia}$ _uma_metodologia_para_gest $\% \mathrm{C} 3 \% \mathrm{~A} 3 \mathrm{o}$ _do_trabalho_interdisciplinar_ em_sa $\overline{\%} \overline{\mathrm{C}} \overline{\mathrm{3}} \% \mathrm{BAde}$.pdf

Artigo apresentado em 26/02/2017

Artigo aprovado em 07/01/2018

Artigo publicado no sistema em 16/04/2018 